\title{
A Few Improvements on the Technique of Skin Transplantation in Mice
}

By

\author{
Sakari Sato, Shingo Kakizaki, Koichi Mizutani, \\ (佐 藤源) (柿崎 真吾) (水谷 恒一) \\ Keizo Miura, and Yoshinobu Ishikawa \\ (三浦慶造) (石川義信) \\ From the Surgical Clinic of Prof. S-T Katsura, \\ Tohoku University Hospital, Sendai
}

(Received for publication, January 22, 1958)

The occasions calling for homotransplantation of skin in animals are recently growing more and more frequent, in the scientific fields, especially, in biology, genetics and medicine.

In the domein of medicine, this process has been taken up as a step in the study of homotransplantation of organs as well. Skin grafting is easier in technical execution than other organ or tissue transplantation, especially in orthotopic grafting. The advantage of the method is easy to observe the subsequent development of the treated site and the functions of the graft. For example, hair growth and pigmentation can be readily examined following skin grafting.

Since Billingham and Medawar ${ }^{1)}$ have described their transplantation technique in detail, improvements (chiefly on the covering materials) have been reported on a few points, ${ }^{2,3), 4)}$ but no essential change has been broght about in the technique. The authors have been achieving a series of improvements and simplifications in the technique during experimental studies for some years.

A curt summary of these achievements have been previously reported ${ }^{5}$, and in this paper, the techniques of skin transplantation of which we are currently adopting, including the improvements achieved after the previous report, are described in detail.

There are several methods in skin grafting, namely, of using either pedicle or free graft, of grafting the skin in any thickness from the whole skin including all the layers down to the epidermis only, of covering the bed to be grafted with one or more than one pieces of transplanted skin and of covering up the whole bed by closely fitting the edges of the skin of the grafted site of the recipient and the skin of the graft (fitted style) or leaving a certain part of the bed uncovered (open style). 
In this report, we will limit ourselves to the transplantation of free whole thickness grafts in fitted style, in respect to the grafting method.

\section{Anaesthesia}

In the earlier stage of our study, we worked with mice, generally, anaesthetized with intra-abdominal injection of $0.15 \mathrm{cc}$. per 10 gram of body weight of nembutal solution of $3 \mathrm{mg}$. in $1 \mathrm{cc}$. in saline, but at present we are operating without any anaesthesia. No inconvenience has been encountered.

\section{Fixing}

Rubber loops are fixed on the four corners of wood plates of about $12 \mathrm{~cm} . \times 13 \mathrm{~cm}$. and an aluminium washing clip is tied to one of the end of the loop. As the rubber loops maintain adequate elasticity, they do not lose their hold by motion of the animal's limbs and such binding does not subject the animals to overstrain (Fig. 1).

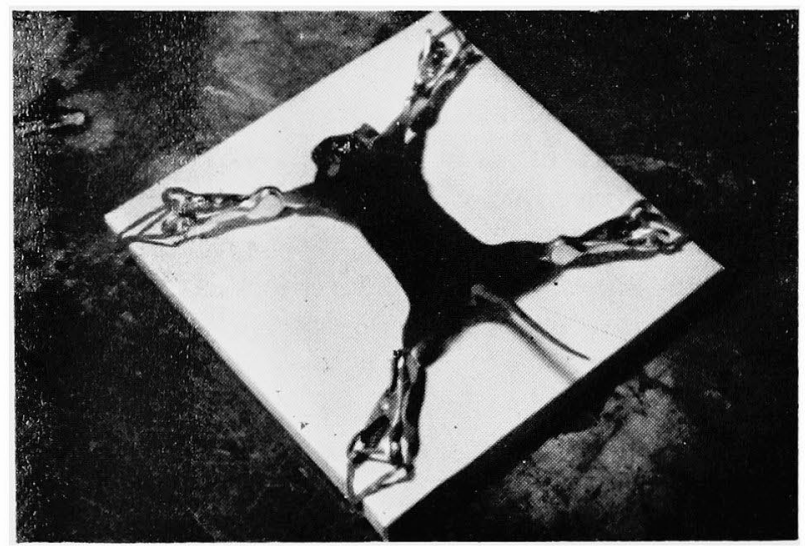

Fig. 1

\section{Preparation of the Graft}

Usually, the grafts are cut out from the skin of the back and the chest of the animal. In the phase of proliferating hair-follicles, however, the skin grows too thick for any transplantation, and such skin specimens must be avoided for experiments. In mice of colored breed, pigments are deposited therein, so that the thickening is seen at a glance, but in white species of mice, we have to pinch up the skin to feel its thickness. In such cases, the blood vessels cannot be visualized due to the thickening of the skin.

At the outset, the hair must be removed, but as shaving causes injury to the skin, we use depilatory cream instead of a razor and the completely beared site is cleaned with humid gauze till scarcely any odor of the cream 
is left. No harmful effect due to the depilatory cream has ever been experienced. Two per cent alcohol solution of mercurochrome is used for disinfection and then the animal is covered under a sheet of vinyl plastic previously soaked in positive ion soap solution and with a hole of suitable area cut at its center. The skin is pinched up with a midget hook-forceps and the specimen of the required area is cut with a fine pair of curved scissors at one stroke.

The epidermis side of the specimen is then stuck on the finger-tip and the panniculus carnosus and the panniculus adiposus must be dissected with the same pair of scissors. If the piece is transplanted without removing these layers, they would act detrimentally except in auto-transplantation, so that the chance of successful results is extremely minimized. The grafts thus prepared are preserved in physiological saline till the bed of transplantation is completed.

Preparation of the Transplantation Bed

The processes of depilation and disinfection are the same as in the preceding. The skin of the site to be grafted is picked up with a midget hook-forceps and a very shallow $V$-shaped cut is made on it with a pair of fine curved scissors. When the cut goes too deep, the bed may be injured, so that it is better to cut it as shallow as possible. First, pick up the apex of the $\mathrm{V}$-shaped cut with the forceps which is held with the left fore-finger and thumb, then the smaller end of the ablator devised by us (Fig. 2) is inserted between the skin and the muscle layer, using the left middle finger as support. When the ablation has gone to some extent, the other end of the ablator is used to peel the skin further, while the ablation is helped on with a pair of fine curved scissors, now and then releasing the pincers hold to control the form of the line of ablation. (Fig. 3). Thus, a bed of any shape and area may be formed at will. In the processes of the operation, proper care is required to avoid injury the muscle layer, because the result is worse when the layer is injured or a blood vessel running on its surface is broken.

\section{Grafting}

The authors have previously sutured the edges with blood vessel threads, but at present we can dispense with sutures by adopting the following procedure. First, absorb the surplus humidity on the surface of the bed with dry aseptic gauze and leave it standing at room temperature for 10 to $15 \mathrm{~min}$. The bed will adequately dry up and dewy lymph will ooze on the raw surface (Fig. 4). Then, stick the graft prepared previously on the operator's finger-tip with the outer skin surface down and trim it into a similar shape but about 10\% larger in dimension than the bed by clipping 


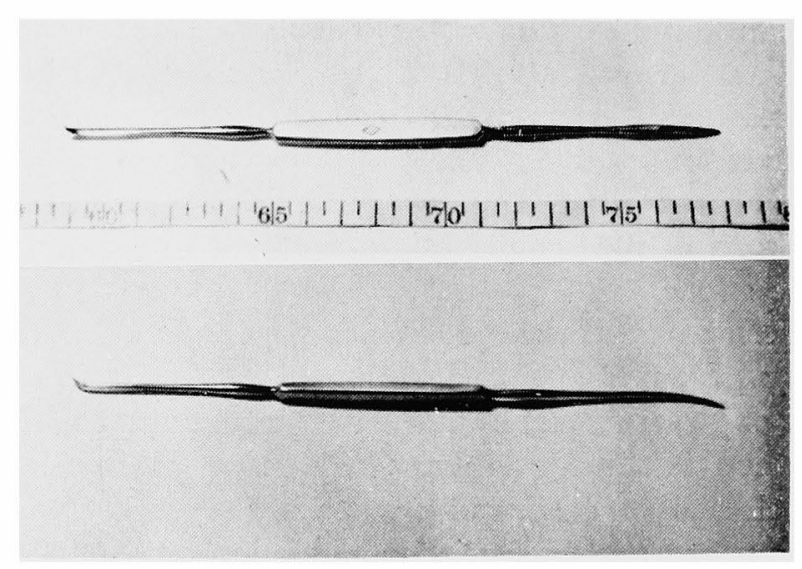

Fig. 2

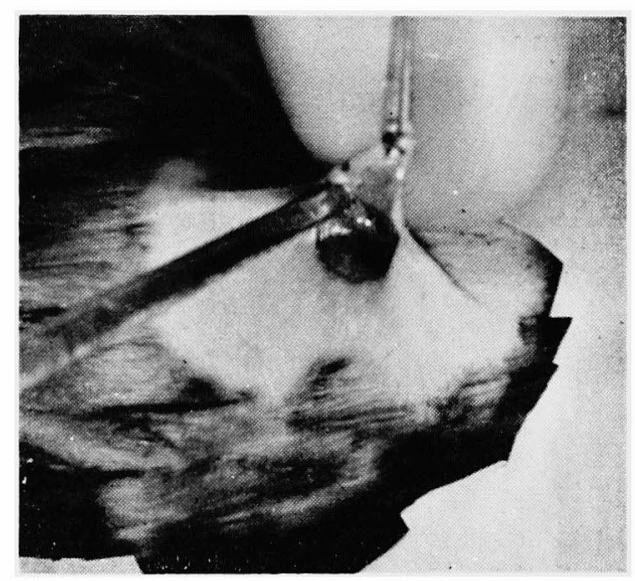

Fig. 3

off the superfluous parts. Press the graft on the finger-tip upon the bed and it will become fixed on it, the edges being adapted. A few minutes after it is transplanted, it becomes firmly adherent to the bed and will not be abraded easily by external forces (Fig. 5).

\section{Covering and Dressing}

Most of the researchers would cover the grafted sites with plastic sheets or fabrics, knit of special fibres, and place elastic adhesive tapes over it to hold them in place. In the earlier stage of our study, we also used to cover the site with polyvinyl or cellophane film preserved in $70 \%$ alcohol, sealed the edges of the film to the skin of the host animal with collodium, then placed a small cotton ball as pressor and wrapped the site including the chest and upper abdomen with adhesive tapes. Such a method, how- 


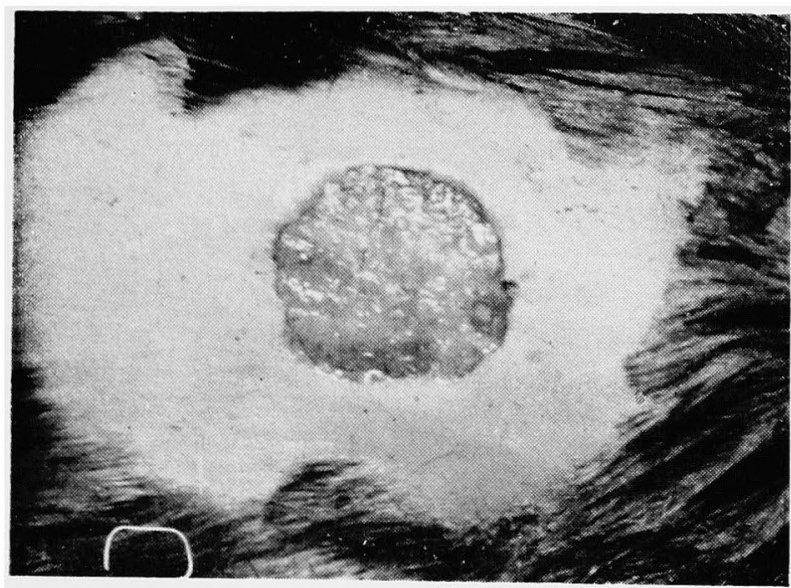

Fig. 4

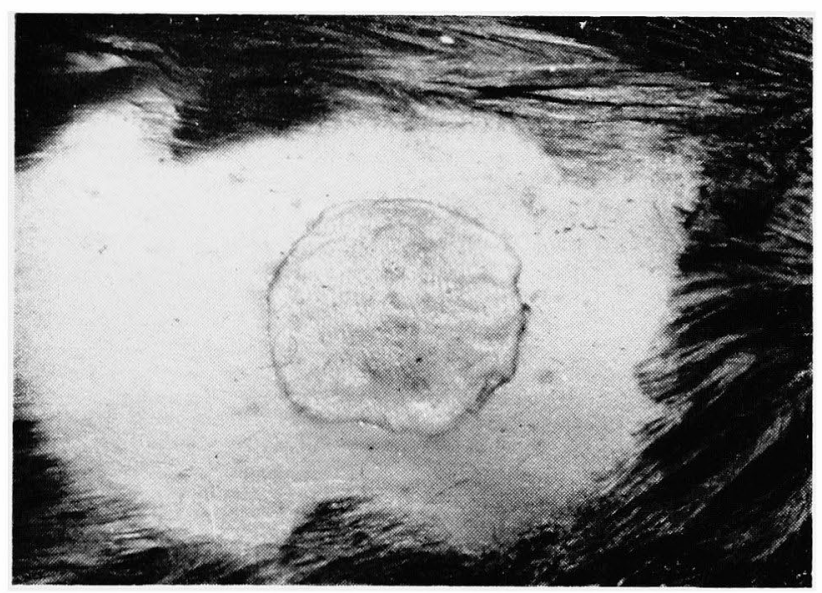

Fig. 5

ever, has the following disadvantages: 1) Before removal of the dressing, we could not only observe the grafts ocularly, but also palpate its hardness for examination. Even when the cotton ball is dispensed with and transparent cellophane tapes were used, we could not palpate it. (For evaluating the degree of vital adhesion, palpation is very serviceable besides ocular examination.) 2) The mice feel unpleasant under the dressing and keep twitching the skin, so that the operated site is hard to keep at rest. 3) Sometimes the inside of sheet becomes humid and multiplies the chance of infection. 4) When removing the dressing 7 to 10 days after the operation, sometimes the sheet is found adhered to the graft and the transplantation is impaired. Particularly, when sutures are not applied, such dressings are nothing but harmful, so we are keeping the animals in a glass 
jar as shown in Fig. 6 without any dressing, but we have had no experience of failure by infection. Dislocation by mechanic stimulus which was very rare, was mostly due to the effort of the animal itself by biting the applied graft. This accident had been effectively suppressed by smearing saturated picric acid around the grafted area.

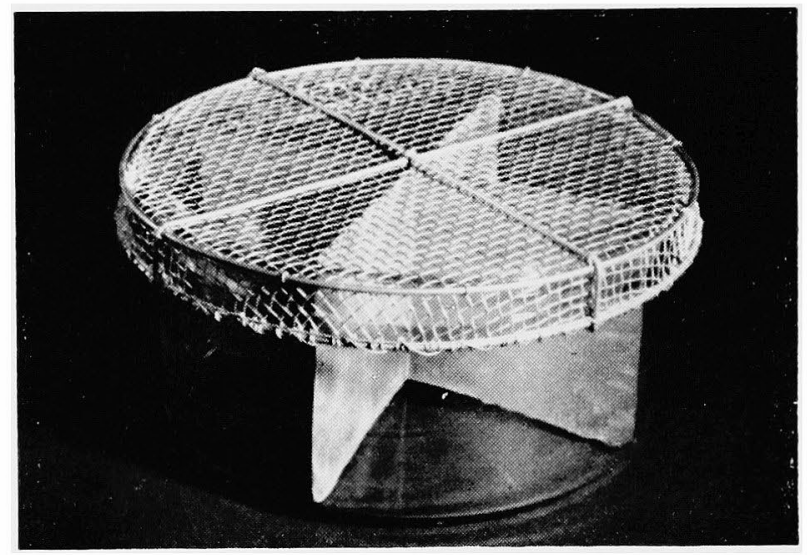

Fig. 6. With tin-plate partitions.

\section{ConcLusion}

The authors have described the technique currently employed in experimental transplantation of free skin in its whole thickness in mice, including the improvements achieved during the past few years of experimental study. The method described herein has the following merits:

1. It is simple in operation.

2. The transplantation is highly successful, without failures due to peeling and infection.

3. Ocular examination and palpation are not hampered from the earliest stage of the transplantation.

\section{References}

1) Billingham \& Medawar, J. Exp. Biol., 1951, 28, 385.

2) Bryant \& Bernard, Transplantation Bulletin, 1955, 2, 133.

3) Silmer, Bond \& Eichwald, Transplantation Bulletin, 1955, 2, 38.

4) Hardin, Transplantation Bulletin, 1954, 1, 186.

5) Ishikawa, Sato \& Abo, Transplantation Bulletin, 1957, 4, 108. 